\title{
O ACÚMULO DE SABERES À EDUCAÇÃO DO PENSAMENTO
}

\author{
Marcelo Alexandre dos SANTOS ${ }^{1}$
}

\begin{abstract}
RESUMO: O presente artigo consiste numa reflexão sobre a extrema valorização atualmente atribuída ao acúmulo de saberes enquanto aquisição de informações, em detrimento de uma educação que priorize a autonomia do pensar e, consequentemente, da emancipação. Pretende-se, portanto, discutir os meios pelos quais este acúmulo se constitui uma exigência e, ao mesmo tempo, uma imposição, influenciando negativamente a ação de pensar dos indivíduos na sociedade contemporânea. Pretende-se também apresentar possíveis caminhos que levem à superação desta problemática e permita atingir um pensar genuíno e emancipador. Para realizar tal intento, recorre-se aos textos dos teóricos frankfurtianos sobretudo Theodor W. Adorno - e aos de Walter O. Kohan (2005), filósofo da atualidade que aborda as principais idéias dos também filósofos Lipman e Deleuze. Reflete também sobre as maneiras pelas quais a educação poderia articular no processo de irrupção de um pensar autônomo, sem distanciar essa autonomia de um processo reflexivo, crítico e criativo. Conclui-se, ao final, que a educação para o pensar só será possível a partir do reconhecimento das conseqüências da mera valorização do acúmulo de saberes e de como se poderia proporcionar a autonomia do pensamento.
\end{abstract}

PALAVRAS-CHAVE: Acúmulo. Saberes. Emancipação. Autonomia. Educação para o pensar.

\section{Esclarecimentos}

Vivemos atualmente uma época em que a aquisição de informações conquistou um lugar de prioridade máxima na sociedade. Essa importância pode ser confirmada não apenas pela afirmação da necessidade instalada, mas, sobretudo, por meio da imensidão de bens culturais disseminados pelos veículos de comunicação de massa, pelas editoras e sistemas de ensino. Pautados em discursos com amparos legais, como a universalização do ensino, estes mecanismos encontram justificativas unânimes para a produção, oferta e implantação de seus acervos e propostas educacionais.

Embora o limite quantitativo de conhecimentos influencie de forma significativa a dimensão do pensamento e do uso que fazemos dele no âmbito das relações sociais e de trabalho, não se pode negar - na mesma proporção - que a pura aquisição técnica destes conhecimentos seja suficiente para desenvolver a tão almejada emancipação nos indivíduos.

No entanto, o que nos comove e nos leva a questionar e refletir é a intensidade da importância atribuída à quantidade de saberes que um indivíduo consiga acumular sobretudo ao longo de sua formação escolar - relegando o movimento contínuo do

\footnotetext{
${ }^{1}$ Mestrando em Educação Escolar. UNESP - Universidade Estadual Paulista. Faculdade de Ciências e Letras Pós-Graduação em Educação Escolar. Araraquara - SP - Brasil. 14800-901 - marceloalesantos@gmail.com
} 
pensamento, na medida em que não se privilegia os momentos e as condições em que esse movimento acontece.

Antes de iniciarmos a discussão, julgamos necessário esclarecermos previamente algumas questões que porventura possam influenciar ou confundir a compreensão do delineamento que intentamos abordar. Primeiramente, é preciso salientar que não pretendemos problematizar nenhum debate entre quantidade versus qualidade, muito menos subjugar o valor do conhecimento enquanto aquisição de saberes. Em segundo, que não temos a pretensão de dogmatizar nenhuma teoria, nem tampouco negar a possibilidade de outras reflexões mais profundas sobre o mesmo objeto que aqui declaramos.

Assim procedendo, ancoramos a presente reflexão na filosofia dos teóricos frankfurtianos - sobretudo Theodor W. Adorno - e nas afirmações do filósofo da atualidade Walter O. Kohan (2005), que aborda as principais idéias dos também filósofos Lipman e Deleuze. Com Adorno, evidenciaremos a presença de uma reprodutibilidade técnica nos saberes transmitidos pela escola, acompanhados de uma conseqüente semiformação (Halbbildung). A partir do segundo, apresentaremos um possível caminho para uma educação para o pensar, também compreendida como uma educação para a emancipação. Gostaríamos de também deixar claro que a escolha pelo legado teórico da Escola de Frankfurt (Frankfurt Schule) deve-se à própria posição que seus pesquisadores - inclusive Adorno - assumiram ao não aceitar o marxismo ortodoxo, ou proceder simplesmente uma mera leitura mecanicista do marxismo. Esta posição pode ser aceita como uma resistência à forma de pensar dogmática e inerte que exclui qualquer outra possibilidade de questionamento sobre si mesma.

Porém, ao anunciar uma educação para o pensar, não significa que procuramos opor o pensar ao saber, negando o saber e afirmando o pensar - pois isso também seria dogmatizar e, consequentemente, interromper o livre movimento do pensamento -, mas, compreender de que maneira o saber pode se constituir uma barreira para a formação de um pensar autônomo.

Para confirmar essa postura é necessário esclarecermos também que o que aqui denominamos cultura do saber refere-se ao privilégio implícito na sociedade atual à aquisição pura e simples de elevado número de conhecimentos formais provindos dos veículos de comunicação e de toda a produção de informações e conhecimentos existentes no mercado. E, na mesma medida, que a educação para o pensar é expressa aqui como a valorização de um processo que ofereça a possibilidade dos indivíduos desenvolverem um pensar que não seja ideologicamente preso, mas que caminhe sempre num processo de auto-renovação. 


\section{Indústria cultural e o apelo ao acúmulo de saberes}

Nunca na história da humanidade houve épocas em que a valorização do maior número possível de conhecimentos acumulados por uma pessoa alcançasse um nível tão elevado como tem ocorrido a partir da metade do século XX. A expansão da oferta de ensino público e de acesso aos meios de comunicação e materiais teóricos têm sido fatores que aceleraram este processo de valorização, acompanhado do apelo do mercado por mão-de-obra cada vez mais qualificada para desempenhar funções que vão desde as linhas de produção das fábricas até a gerência e formação contínua dos operários. O avanço tecnológico principalmente com o advento da informatização - acaba por consolidar esta exigência do mercado capitalista.

Concomitante a este processo, haverá uma procura exacerbada por parte da sociedade por uma educação que ofereça condições necessárias para competir na busca de empregos. Porém, a formação escolar básica não é vista como suficiente para suprir a carência de informações cada vez mais exigida, nem a universidade está universalizada a ponto de garantir o acesso de todas as classes sociais. Ocorre, então, uma tremenda oferta de cursos rápidos, na maioria técnicos, como forma de oportunidade para aqueles que não têm o privilégio de uma formação rigorosamente acentuada.

Diante disso poder-se-ia indagar: mas não é importante para a formação do próprio indivíduo esta busca e acúmulo de saberes? E a resposta seria: o problema não se encontra simplesmente na questão da quantidade destes saberes, mas na qualidade e na forma do conteúdo destes, que, na verdade, impede aquilo que sempre a educação procurou promover e que, de fato, raras vezes conseguiu: a emancipação do indivíduo.

Para clarear esta discussão, recorreremos aos estudos da teoria crítica mediante algumas afirmações do filósofo Adorno que contribuem para compreender o problema da aquisição de conhecimentos, sobretudo por meio da maneira acima abordada.

No ano de 1947 Adorno e Horkheimer lançam a obra "Dialética do Esclarecimento fragmentos filosóficos” (1985), evidenciando pela primeira vez o conceito de Indústria Cultural, em substituição à expressão cultura de massas, que oferecia erroneamente a idéia de que se tratava de uma cultura produzida pelas massas e que, na verdade, consiste numa cultura criada ideologicamente pela classe dominante e imposta às massas também por meio da cultura.

A Indústria Cultural influencia diretamente a formação (Bildung) do indivíduo quando provoca aquilo que Adorno e Horkheimer descreveram também em "Dialética do 
Esclarecimento": a Razão Instrumental, ou, Instrumentalização da Razão, que pode ser compreendida como o ofuscamento da realidade por meio do controle da razão. Este processo é explanado na obra pelos autores através de um contraste entre razão e mito, na tentativa de resgatar a razão enquanto esclarecimento e libertação.

A problemática de toda esta situação a que se submeteu o desenvolvimento da razão influenciará o processo de formação (Bildung) dos indivíduos na sociedade e, por conseqüência, a condição e a maneira de pensar. Na formação (Bildung), ocorre um empobrecimento da experiência (Erfahrung) e uma crescente desvalorização das preocupações com o desenvolvimento do pensar. É o nascimento da semiformação (Halbbildung), que pode ser definida da seguinte forma:

Compreende-se o conceito de semiformação justamente pela tentativa de oferecimento de uma formação educacional que se faz passar pela verdadeira condição de emancipação dos indivíduos quando, na realidade, contribui decisivamente tanto para a reprodução da miséria espiritual como para a manutenção da barbárie social. E o contexto social no qual a barbárie é continuamente reiterada é o da indústria cultural hegemônica. (ZUIN, 2001, p. 10).

A semiformação (Halbbildung) é reforçada a partir de uma mudança no comportamento dos indivíduos. Como diz Pucci, Ramos-de-Oliveira e Zuin (1999, p.119), “[...] São atitudes comuns do indivíduo semiculto aquelas que dizem respeito à falta de tempo em proporcionar algum tipo de aprofundamento sobre qualquer assunto.” A facilidade de acesso e a rapidez com que a Indústria Cultural oferece seus produtos culturais vão, momentaneamente, suprir as necessidades emergenciais destes indivíduos, levando-os à satisfação por terem adquirido um conhecimento exigido de forma prática e confortável, uma vez que na maioria das vezes não precisam nem ao menos se deslocar de sua casa para realizarem tal ação. Esse tipo de comportamento, como diz Pucci, Ramos-de-Oliveira e Zuin (1999, p.119): “[...] é cotidianamente reforçado pela mídia, sob a forma de jornais, revistas, e biografias romanceadas que fornecem dados superficiais sobre personagens e fatos, perdendose a possibilidade do exercício do raciocínio crítico, que se converte em mera curiosidade.”

Não há mais dúvidas de que a quantidade de saberes acumulados - sobretudo aqueles disseminados pela Indústria Cultural - é a principal defesa do mundo capitalista nos dias atuais. Também é evidente a decadência do processo de emancipação por meio da cultura e da educação vivida pela sociedade em meio à exposição aos bens culturais oferecidos no mercado. Essa tendência crescente ao acúmulo de saberes pode ser confirmada nas palavras de Zuin quando afirma: 
Atualmente o que interessa é o acúmulo do maior número de informações no menor espaço de tempo possível, mediante o consumo de produtos semiculturais que parecem fornecer de antemão as respostas para todas as nossas dúvidas, bem como o atendimento dos nossos mais recônditos desejos. Os indivíduos, tanto cognitiva quanto afetivamente, são educados para subordinarem-se ao processo de semiformação cultural que impinge a exaltação da adaptação e do conformismo, ou seja, das consciências felizes ao invés do discernimento e do inconformismo. (ZUIN, 1997, p.118)

A partir dessa realidade que se faz tão presente nos dias atuais, nos colocamos mais uma vez a questionar quais as possibilidades de desenvolvermos uma educação que caminhe contra a imensa maré da Indústria Cultural. Uma educação que privilegie a emergência de um pensamento reflexivo e crítico em todas as ações que se proponha a fazer. Embora esta seja uma tarefa tão difícil quanto perigosa, é também, diante dessa situação, definitivamente necessária.

No entanto, antes de discutirmos mais precisamente as condições de um pensar genuíno, é necessário retomar algumas considerações importantes acerca do objetivo da educação feitas por Adorno (2000) e Kant (1985).

Adorno e Hellmut Becker, num debate em 1969 intitulado "Educação e Emancipação” (2000) discutem acerca da questão da emancipação. Durante o debate, Becker atenta que este é um problema não apenas da Alemanha, de onde tiravam os exemplos mais significativos, mas um problema mundial. Acrescentando-o, podemos dizer que o problema da emancipação é hoje extremamente atual, apesar do ofuscamento da realidade negar sua existência. E o problema se agrava mais ainda quando ocorre caladamente aquilo que Becker afirma nesse mesmo debate: “[...] num mundo como o nosso, o apelo à emancipação pode ser uma espécie de disfarce da manutenção geral de um estado de menoridade.” (ADORNO, 2000, p.180).

No entanto esta já era uma questão recorrente na história. Kant (1985) já alertava para a culpabilidade do próprio homem pelo seu estado de menoridade, inclusive quando se recusa a tomar decisões por conta própria. Nesta situação, a própria ação de pensar é transferida para a responsabilidade de outro indivíduo. E o que chama a atenção é que este estado de menoridade envolve não apenas a classe submissa, mas também aquela que está no controle destas. Como explica Kant (1985), o homem no estado de menoridade e, portanto, distante da emancipação, declara: "Não tenho necessidade de pensar, quando posso simplesmente pagar; outros se encarregarão em meu lugar dos negócios desagradáveis.” (KANT, 1985, p.102). 
Porém, o que mais encontramos atualmente é uma imensa gama de propostas educacionais inovadoras implantadas com o intuito de salvar a educação do caos em que se instalou. É notório o fato que em todas elas os objetivos sempre se situam nos fins a que se destinam, nas metas a serem atingidas e muito pouco, ou quase nunca, nos mecanismos do processo por onde passam. Sem a inflexão ao processo, há uma exclusão das pessoas que mais necessitam de uma participação efetiva: a comunidade escolar. Sem esta participação nos momentos de reflexão, criação e tomadas de decisões, a educação deixa de emancipar e começa a comandar, e esta é uma característica típica da pedagogia moderna.

\section{Os caminhos para uma educação do pensamento}

A busca pelas instancias de uma educação emancipadora tem sido feita por meio de propostas inovadoras baseadas na pedagogia moderna.

Entre essas propostas têm se destacado pelo mundo o programa Filosofia para Crianças, o $\mathrm{FpC}^{2}$, do filósofo norte-americano Matthew Lipman. Vejamos, em linhas gerais, em que consiste este programa educacional.

As primeiras considerações feitas por Lipman acerca do pensar remetem às décadas de 60 e 70, época em que alguns educadores iniciaram questões quanto às possibilidades de se ensinar os alunos a pensarem, ou seja, ensinar as habilidades de pensamento paralelamente ao currículo escolar. Para isso, seria necessária a introdução de uma disciplina que permitisse essa ação de forma suficientemente produtiva. Essa disciplina seria a Filosofia. Só ela seria capaz de oferecer as condições necessárias para o desenvolvimento de um pensar verdadeiro e correto.

Diante dessas conclusões Lipman elabora e implanta em algumas escolas americanas o programa FpC, com toda uma estrutura material curricular para os alunos e de formação para professores que atuariam diretamente nele. Porém, não se resume apenas nisso.

Para sua efetivação, o FpC exige uma série de transformações significativas, começando pela transformação da sala de aula em uma comunidade de investigação, fluída sob o predomínio do diálogo, atingindo em maior âmbito possível a dimensão da autonomia de cada membro. Abre-se destaque ao conceito de autonomia a que Lipman (1995) se refere. Para ele, esta autonomia consiste na possibilidade de pensar por si mesmo e não apenas

\footnotetext{
${ }^{2}$ FpC é a sigla de Filosofia para Crianças, programa filosófico - educacional criado por Matthew Lipman e implantado em determinadas escolas americanas e posteriormente em outros países da América e Europa.
} 
repetir o que dizem ou pensam outras pessoas. Para ele essa consideração é necessária pelo fato de muitas pessoas associarem autonomia a individualismo, onde o pensador, de forma crítica, se protege por meio de argumentos de possíveis questionamentos contrários aos seus.

Além da transformação da sala de aula em uma comunidade de investigação, Lipman (1990) substitui os livros didáticos pelas novelas filosóficas, que consistem numa espécie de romances onde os personagens são sempre crianças e dialogam entre si sobre uma determinada questão, mediadas por um intenso rigor filosófico, formando uma comunidade de investigação. Segundo Lipman (1990) essa é uma forma de tornar a abordagem filosófica mais próxima da criança e ao mesmo tempo mais interessante e significativa.

Outra exigência do programa $\mathrm{FpC}$, diz respeito à formação dos professores que atuam diretamente em sala de aula com os alunos, que é realizada a partir do cumprimento de uma ordem consecutiva de passos, acompanhados por monitores com extenso currículo na atuação filosófica e que são responsáveis por conduzir e avaliar estes professores quanto ao seguimento dos passos (LIPMAN, 1990).

Soma-se à formação e ao trabalho do professor no FpC um manual contendo exercícios para orientá-lo e que podem ser utilizados nas abordagens e discussões com o intuito de tornar o diálogo promissor e com um maior rigor filosófico (LIPMAN, 1990).

Diante do exposto, nota-se que o programa FpC parece bastante preocupado com a melhoria da problemática educacional e extremamente eficaz para o desenvolvimento de uma educação para o pensar. Disso, Lipman tem toda certeza. No entanto, não parece ser isso o que ocorre com o FpC.

Para analisar melhor as possibilidades do programa filosófico de Lipman, vejamos o que nos tem a dizer o filósofo Walter O. Kohan.

Ao analisar o FpC., Kohan (2005) afirma que Lipman possui uma visão idealizada e iluminista da escola, atribuindo-a um caráter de reprodução ao considerá-la como centro de preparação para uma vida em sociedade. Para Kohan (2005), isso pode ser expresso quando se analisa o papel do professor no programa FpC que, utilizando suas palavras, atua como árbitro na condução do processo, principalmente nas discussões, e, quanto menos participar, melhor desempenhará seu papel. Assim, o bom professor é aquele que se dilui em meio à comunidade de investigação, é alguém que um dia os alunos não mais precisarão porque já terão internalizado o modelo que ensinava. A questão do modelo é tida como um tópico interessante no programa de Lipman (KOHAN, 2005).

Quando Lipman exige a presença dos monitores experts em filosofia para atuarem na formação dos professores, sem nem ao menos consultá-los, ocorre, segundo Kohan (2005) 
uma desvalorização do professor, sobretudo diante das tomadas de decisões. Kohan (2005) chama os professores, neste caso, de profanos, ou seja, aqueles que por não dominarem o conhecimento filosófico são privados de participarem da elaboração intelectual do seu trabalho. Em tal situação, ele reitera:

[...] um programa que diz superar a filosofia tradicional, que afirma apostar na sensibilidade filosófica como condição primeira da prática docente, acaba solicitando os serviços de uma formação clássica; um programa que diz valorizar o docente acaba submetendo-o duplamente: a uma textualidade já pronta que ele deve aplicar e a uma autoridade externa, a do expert, que determinará a qualidade filosófica dessa aplicação. (KOHAN, 2005, p.100).

A não participação dos professores nas decisões do FpC exime também a possibilidade de pensamento dos mesmos. Mais uma vez esta tarefa é transferida a outras pessoas.

Uma outra questão criticada por Kohan (2005) quanto ao programa FpC consiste na compreensão que Lipman faz do pensamento quando considera-o como um conjunto de habilidades que podem ser desenvolvidas por meio de uma técnica. O que Kohan quer dizer é que o pensamento deve conter uma dimensão voltada a provocar experiência no indivíduo que o realiza. Esta experiência é a transformação em si. E por isso afirma; “[...] A experiência, não a técnica, está na base de um tal pensar.” (KOHAN, 2005, p.108). Ao considerarmos o pensamento como habilidade em detrimento da experiência que ele possa provocar, estamos impedindo suas condições de transformação (KOHAN, 2005). E com a experiência ocorre o mesmo que acontece com o perguntar: ninguém pode fazer perguntas pelo outro, ninguém pode viver experiências pelo outro.

Neste momento surge a questão: se o programa filosófico de Lipman que busca o desenvolvimento de um pensar acaba por não realizar devidamente esta tarefa, como deveria ser então uma educação para o pensar? Kohan (2005) busca na filosofia de Gilles Deleuze as possibilidades para esse caminho.

Ao afirmar esta desvalorização do pensar na atualidade, Kohan (2005) reconhece que se trata de uma duplicidade controversa, pois paralelo a ela, nota-se a insurgência extrema como já temos afirmado - de programas e projetos imbuídos do objetivo de favorecer o pensamento. Para explicar esta realidade, o autor apresenta duas possibilidades. A primeira se refere à tentativa de restaurar um espaço protagonista como resposta ao clima dominante. A segunda é a de que estas medidas carregam uma versão desvalorizada do pensamento, onde este é reduzido a uma imagem mansa e inofensiva ao estado de coisas dominantes. Neste 
caso, as ações desenvolvidas provocam o esgotamento e uma ausência do pensar, sendo retirado dele aquilo que confere sua possibilidade de transformação própria e da subjetividade que realiza. Ocorre, portanto, uma negação do pensamento (KOHAN, 2005).

Ao serem diluídas em ações cotidianas projetadas pela ciência, fortalecidas pela Indústria Cultural e amparadas pela mídia, atingindo uma parcela cada vez maior da sociedade, as formas de desvalorização do pensamento são apreendidas por todos os indivíduos inconscientemente, tornando-se parte integrante de suas atitudes. Este processo desencadeia a formação de uma cultura típica das sociedades de consumo, promotora da reprodutibilidade técnica e de conformidade às condições de sobrevivência impostas pelas classes dominantes. Esta cultura de desvalorização do pensar apóia-se e é recebida com tamanha complacência pela supervalorização do saber que, por sua, vez encontra-se carregado da mesma postura bloqueadora do pensamento.

Algo que chama a atenção quando nos colocamos a questionar as possibilidades de desenvolvimento do pensar é o fato de que, historicamente, todos aqueles que se puseram a fazer esta tarefa sempre recorreram à filosofia como mediadora desse processo, utilizando-a incondicionalmente. Na realidade, o pensar é uma atitude tradicionalmente filosófica, ou, como diz Kohan (2005), é uma preocupação literalmente clássica da filosofia. Porém, ao mesmo tempo em que se preocupa com as modalidades do pensamento, dependendo da posição tomada por seus pensadores a respeito destas mesmas modalidades, a filosofia pode tanto contribuir para o desenvolvimento do pensamento quanto emperrá-lo em seu processo de renovação.

Aquela filosofia que se coloca como líder do pensamento e controladora das rédeas do sentido que deve ser seguido para que seja digno de seu rigor e que, por conseguinte, legitima, julga e estabelece caminhos previamente, é uma filosofia que atende às exigências das condições dominantes impostas, apesar de se defender insistentemente como contrária a estas exigências.

Diante de toda a questão já abordada, uma coisa é certa: o pensar não está dado, ele precisa ser levado a surgir, o que só acontece a partir do encontro entre a subjetividade de quem se coloca a pensar e um motivo indeterminado que o força a pensar, que motiva o irromper do pensamento. Nesta perspectiva é possível afirmar que o pensar é um problematizar que promove uma experiência no indivíduo, conduzindo-o à transformação.

Neste sentido, quando um método, uma proposta ou uma técnica se apresenta como meio de desenvolvimento do pensar, para que isso acontecesse, seria necessário que estes 
meios antecipassem algo inantecipável. Sendo assim, como Kohan (2005) conclui, não existem formas predeterminadas que consigam produzir o pensar.

Portanto, diante de todo o exposto, acreditamos que o caminho para a emancipação por meio da educação não reside apenas no oferecimento em massa de bens culturais, mas principalmente na maneira como estes bens são construídos e apropriados pela sociedade. É na relação com os saberes adquiridos que o indivíduo construirá ou não sua autonomia. A autonomia do pensar. A emancipação.

\section{FROM THE KNOWLEDGE'S ACCUMULATION TO THE THINKING EDUCATION}

ABSTRACT: This article is a reflection of the extreme value currently attributed to the accumulation of knowledge while acquiring information, rather than an education that emphasizes the autonomy of thinking and, consequently, of emancipation. It is intended, therefore, discuss the means by which this accumulation is a requirement and at the same time, a levy, which negatively affects the action of thinking of individuals in contemporary society. The aim is to present possible paths that lead to overcome this problem and to attain a genuine thinking and emancipatory. To achieve this purpose, it is through the texts of theoretical Frankfurtian - especially Theodor W. Adorno - and Walter O. Kohan (2005), philosopher of our time addressing the main ideas of the philosophers also Lipman and Deleuze. It also reflects on the ways in which education could articulate the process of emergence of an autonomous thinking, without the distance range of a reflective process, critical and creative. It is the end, that education for thinking is only possible from the recognition of the consequences of focusing the accumulation of knowledge and how it could provide the autonomy of thought

KEYWORDS: Accumulation. Knowledge. Emancipation. Autonomy. Education for thinking

\section{REFERÊNCIAS}

ADORNO, T. W. Educação e emancipação. In: ADORNO, T. W. Educação e emancipação. 2 ed. Tradução de Wolfgang Leo Maar. São Paulo: Paz e Terra, 2000.

ADORNO, T. W.; HORKHEIMER, M. Dialética do esclarecimento. Tradução de Guido Antônio de Almeida. Rio de Janeiro: J. Zahar, 1985.

KANT, I. Resposta à pergunta: o que é esclarecimento? Tradução de Floriano de Souza Fernandez. Edição bilíngüe. Petrópolis: Vozes, 1985. (Textos Seletos).

KOHAN, W. O. Infância: entre educação e filosofia. São Paulo: Autêntica, 2005. 
LIPMAN, M. O pensar na educação. Tradução de Ann Mary Fighiera Perpétuo. Petrópolis: Vozes, 1995.

A filosofia vai à escola. Tradução de Maria Elice de Brzezinski e Lucia Maria Silva Kremer. São Paulo: Summus, 1990.

PUCCI, B.; RAMOS-DE-OLIVEIRA, N; ZUIN, A. A. S. Adorno: o poder educativo do pensamento crítico. Petrópolis: Vozes, 1999.

ZUIN, A. A. S. Sobre a atualidade do conceito de Indústria Cultural. Cadernos Cedes, Campinas, n. 54, p. 9-18, 2001.

A indústria cultural e as consciências felizes: psiques reificadas em escala global. In: ZUIN, A. A. S.; PUCCI, B; OLIVEIRA, N. R. de. (Org.). A educação danificada: contribuições à teoria crítica da educação. Petrópolis: Vozes, 1997. 